\title{
Riscos do trabalho dos motociclistas profissionais: estratégias de prevenção e regulação
}

\author{
Lucas Gabriel de Almeida Carvalho \\ Graduado em Engenharia de Saúde e Segurança - \\ Universidade Federal de Itajubá, Campus Itabira, Itabira/MG \\ 凹carvalho27@gmail.com \\ Geraldo Fabiano de Souza Moraes \\ Doutor em Ciências da Reabilitação e Professor do Curso de Engenharia de Saúde e Segurança - \\ Universidade Federal de Itajubá, Campus Itabira, Itabira/MG \\ \geraldofsmoraes@gmail.com \\ Davidson Passos Mendes \\ Doutor em Educação e Professor do Curso de Engenharia de Saúde e Segurança - \\ Universidade Federal de Itajubá, Campus Itabira, Itabira/MG \\ $\square$ davidsonpmendes@gmail.com
}

Recebido em 29 de agosto de 2017

Aceito em 28 de setembro de 2017

\begin{abstract}
Resumo: Pesquisa Qualitativa.

\section{Risks of work of motorcycle couriers: prevention strategies and regulation}

Este estudo teve por objetivo reconhecer, de acordo com o ponto de vista dos entrevistados, as formas de prevenção empregadas e as causas de acidentes de colisão ocorridos com motociclistas profissionais (MP) durante o período de trabalho. A pesquisa foi realizada numa cidade de grande porte do interior de Minas Gerais, utilizando-se da metodologia qualitativa "História de Vida" e entrevistados três MP, que foram diferenciados segundo suas experiências com o tipo de acidente vivenciado. Os resultados revelaram que: 1) a escolha pelo trabalho se dá em função da dificuldade de acesso da população jovem e masculina no mercado formal de trabalho; 2) os riscos assumidos se dão em razão da intensificação e densificação do trabalho estabelecidos pela Organização do Trabalho - baixo valor unitário do serviço, daí a necessidade de alta produção; 3) o meio social cria a demanda pelo serviço, porém, não abre o espaço social efetivo para a sua estruturação e funcionamento; 4) há conflitos no trânsito (interfaces com os outros motoristas), principalmente, em razão da desatenção e da falta de conhecimento da atividade dos MP. Novas soluções são necessárias para reverter os constrangimentos materiais, organizacionais e sociais a que os motociclistas profissionais estão expostos. Essa deve ser uma construção coletiva com o uso de saberes dos atores envolvidos que reflitam em saúde e segurança para este contexto produtivo.

Palavras-chave: Acidente de Trânsito, Motoboy, Saúde do Trabalhador, Acidente de Trabalho,

\begin{abstract}
:
This study aimed to recognize, according to the interviewees' point of view, the forms of prevention employed and the causes of collision accidents that occurred with motorcycle couriers (MC) during the work period. The research was conducted in a large city in the interior of Minas Gerais, using the qualitative methodology "History of Life" and interviewed three MC, who were differentiated
\end{abstract}


according to their experiences with the type of accident experienced. The results revealed that: 1) the choice for work is due to the difficulty of access of the young and male population to the formal labor market; 2) the risks assumed are due to the intensification and densification of work established by the Labor Organization - low unit value of the service, hence the need for high production; 3) the social environment creates the demand for the service, but does not open the effective social space for its structure and functioning; 4) there are traffic conflicts (interfaces with other drivers), mainly due to inattention and lack of knowledge of MC activity. New solutions are needed to reverse the material, organizational, and social constraints facing MC. This should be a collective construction with the use of the knowledge of the actors involved that reflect on health and safety for this productive context.

Keywords: Traffic accident, Motorcycle courier, Occupational health, Occupational accident, Qualitative research.

\title{
Riesgos de trabajo de los motociclistas profesionales: estrategias de prevención y regulación
}

\begin{abstract}
Resumen:
Este estudio tuvo como objetivo reconocer, de acuerdo con el punto de vista de los entrevistados, las formas de prevención empleadas y las causas de accidentes de colisión ocurridos con motociclistas profesionales (MP) durante el período de trabajo. La investigación fue realizada en una ciudad de gran porte del interior de Minas Gerais, utilizando la metodología cualitativa "Historia de Vida" y entrevistados tres MP, que fueron diferenciados según sus experiencias con el tipo de accidente vivido. Los resultados revelaron que: 1) la elección por el trabajo se da en función de la dificultad de acceso de la población joven y masculina en el mercado formal de trabajo; 2) los riesgos asumidos se dan en razón de la intensificación y densificación del trabajo establecidos por la Organización del Trabajo - bajo valor unitario del servicio, de ahí la necesidad de alta producción; 3) el medio social crea la demanda por el servicio, pero no abre el espacio social efectivo para su estructuración y funcionamiento; 4) hay conflictos en el tránsito (interfaces con los otros conductores), principalmente, en razón de la desatención y de la falta de conocimiento de la actividad de los MP. Las nuevas soluciones son necesarias para revertir las limitaciones materiales, organizacionales y sociales a las que están expuestos los MP. Esta debe ser una construcción colectiva con el uso de saberes de los actores involucrados que reflejen en salud y seguridad para este contexto productivo. Palabras clave: Accidente de tránsito, Mensajero moto, Salud ocupacional, Accidente laboral, Investigación cualitativa.
\end{abstract}

\section{INTRODUÇÃO}

O mundo capitalista tem contribuído de forma contundente na forma de ser e de fazer o trabalho e provocado conflitos e debates sobre as relações entre trabalho-capital. 0 trabalho constitui um dos vetores essenciais na estruturação das sociedades, o que nos leva a refletir sobre aspectos e processos relacionados à sua precarização, individualização das relações de trabalho, insegurança e vulnerabilidades, além de suas possibilidades de fragmentação da sociedade ou de integração social (TONI, 2003). Diante disso, existem implicações sociais atribuídas às mudanças nas formas de organizá-lo e de geri-lo. 


\section{Carvalho et al.}

A sociedade atual se caracteriza pela urgência, instantaneidade e velocidade, o que traz a necessidade de profissionais que atendam estas exigências. De acordo com Soares et al. (2011), diante dessas demandas, o surgimento dos motociclistas profissionais (MP's) foi de extrema importância para atendê-las. Por se tratar de um veículo com facilidade de compra, graças a acesso ao crédito e ampliação dos prazos de pagamento, de acordo com dados do DENATRAN ${ }^{1}$, o uso de motocicletas no Brasil apresentou uma tendência de crescimento. Além de um meio de transporte pessoal, as motocicletas servem como instrumentos de trabalho, sendo utilizadas para entregas de mercadorias (motociclistas profissionais), ou transporte de pessoas (moto-táxis).

De acordo com Soares et al. (2011), os MP's se destacam nas grandes cidades em razão de uma maior exigência da sociedade local por mobilidade, com rapidez e agilidade, frente ao trânsito caótico, submetidos às precárias condições de trabalho e com alto risco de acidentes de trânsito.

No Brasil, segundo dados do Ministério da Saúde², em maio de 2015, o número de internações hospitalares após acidentes com motos cresceu 115\% nos últimos 6 anos, o qual representa metade do total de internações por acidentes de trânsito no país. Em Minas Gerais, como relatado no estudo de Diniz, Assunção e Lima (2005, p. 906), em meados de 1999 já havia um expressivo crescimento do setor de motociclistas profissionais, acidentes graves e fatais e ausência de regulamentação das condições de trabalho e dos serviços realizados por esses trabalhadores.

Em relação ao trabalho dos profissionais que utilizam motos para desenvolvê-lo, foi descrito no estudo de Drumond Moraes (2008), que por causa do ritmo de trabalho, o qual toma uma forma de ser paradoxal entre angústias e prazeres, os MP's aprenderam a transitar em meios intransitáveis, transformando essa forma de ser em uma ferramenta que atende à demanda de produção.

Realizando atos que muitas vezes vão contra as leis de trânsito e podem ser preditores de acidentes, tornam o ponto de vista das pessoas sobre os MP algo dicotômico, pois mesmo sendo alvo de críticas, também são caracterizados como peças fundamentais

\footnotetext{
${ }^{1}$ Dados obtidos no site: http://www.denatran.gov.br/index.php/estatistica/237-frota-veiculos (Acesso em $15 / 10 / 2016)$

${ }^{2}$ Informações obtidas no site http://www.blog.saude.gov.br/35535-brasil-e-o-quinto-pais-nomundoemmortes-por-acidentes-no-transito.html (Acesso em 23/05/2016).
} 
para atender as demandas sociais contemporâneas, assim como um entrevistado no estudo de Veronese e Oliveira (2006, p. 2718), menciona:

\begin{abstract}
"A sociedade criou o motoboy ${ }^{3}$, criou todo esse comodismo, e a própria sociedade é que discrimina o motoboy. Mas, aquela mesma pessoa que te xinga na rua, que, quando tu passas, toca no retrovisor dela, ela quer receber o remédio, o documento. Aí, ela te chama pra fazer aquele serviço com pressa. Então, no trânsito, ela te discrimina; mas, para ser bem atendido, aí, ela te chama em casa".
\end{abstract}

Em relação aos acidentes sofridos pelos MP, segundo Silva, Soares e Andrade (2008, p. 137): "A constatação da maior ocorrência de acidentes de trânsito durante o exercício profissional reforça a susceptibilidade dos motoboys a esses eventos por aspectos inerentes à profissão [...]", explicitando assim que o risco está relacionado diretamente com o trabalho dos MP devido ao tipo de trânsito em que eles estão inseridos, o qual, juntamente com condições precárias das vias urbanas, tem como possível consequência o alto número de acidentes com óbito.

Conforme a Organização Mundial da Saúde (OMS) ${ }^{4}$, mais de 1 milhão de pessoas no mundo morrem por ano em acidentes de trânsito, e cerca de 50 milhões ficam feridas, sendo em sua maioria jovens, gerando sofrimento familiar. Os motociclistas são particularmente vulneráveis e representam até $23 \%$ de todas as mortes por acidentes de trânsito.

Como uma forma contributiva do governo para a sensibilização quanto a essa situação, o setor de saúde poderia ter participação por meio de produção de notificações reais do problema, e traçar estratégias para solucioná-los, o que auxiliaria nas medidas para resolução do problema (TEIXEIRA et al., 2014).

Há uma necessidade de uma abordagem global desta profissão no sentido do entendimento histórico de sua formação e como se apresenta no cotidiano. Desta forma, pode-se pensar em nível de saúde e segurança para esses profissionais, pois com o aumento de demanda do mundo globalizado, bem como o contexto de crise, nota-se um agravamento em nível de densificação e intensificação da forma de se trabalhar, a fim de se alcançar os anseios da sociedade. Porém, isso repercute diretamente em nível social, no agravamento e

\footnotetext{
${ }^{3}$ Motoboy: denominação popular dos motociclistas profissionais.

${ }^{4}$ Informações do site http://www.who.int/mediacentre/factsheets/fs358/en/ (Acesso em 05/11/2016).
} 


\section{Carvalho et al.}

precarização das condições de trabalho, bem como no enfrentamento e negligência dos motociclistas profissionais em "seu fazer" do dia a dia.

Portanto, o objetivo desse artigo foi, por meio da abordagem metodológica qualitativa, expor o ponto de vista dos motociclistas profissionais sobre os riscos de acidentes de colisão na sua atividade e as formas utilizadas para a prevenção.

\section{O MÉTODO}

Advinda de pesquisas qualitativas, a História de Vida é uma metodologia que utiliza de registros por meio de entrevistas, testemunhos sobre acontecimentos, modos de vida ou outros aspectos de histórias do cotidiano. Como exposto por Menegolo et al. (2006), ela possibilita o pesquisador a adotar não somente materiais escritos, mas também descrições orais de pessoas que vivenciaram fatos relacionados ao tema, permitindo com isso o resgate de informações específicas sobre a história.

Pesquisas deste tipo têm como intenção primária a análise do ponto de vista dos sujeitos sobre seu ambiente e suas complexidades. Por meio de uma introspecção, o entrevistado expõe seu ponto de vista a respeito de algo que fez parte da sua vivência, no qual, no relato de vida o que importa, afirma Glat (1989, apud. Spindola e Santos, 2003, p. 121) "[...] é o ponto de vista do sujeito. O objetivo desse tipo de estudo é justamente apreender e compreender a vida conforme ela é relatada e interpretada pelo próprio ator“, e que, "[...] tem como consequência tirar o pesquisador de seu pedestal de 'dono do saber ${ }^{\text {e }}$ ouvir o que o sujeito tem a dizer sobre ele mesmo: o que ele acredita que seja importante sobre sua vida" (GLAT, 1989, apud. Spindola e Santos, 2003, p. 121).

Esta metodologia qualitativa foi escolhida para este estudo pois, de acordo com Spindola e Santos (2003), preocupa-se com fatos não quantificáveis que respondem questões particulares, trabalhando com uma gama extensa de significados, crenças e valores, que correspondem a um espaço mais intenso das relações e dos fenômenos que não podem ser reduzidos à operação de variáveis. 
Uma amostra de três motociclistas profissionais foi elencada pelos pesquisadores, a fim de expressarem de modo representativo em nível daqueles que nunca sofreram acidentes, os que já sofreram e voltaram ao trabalho e os que já sofreram acidentes e ficaram incapacitados a exercerem novamente a profissão. Vale ressaltar, que a população existente era composta de motociclistas profissionais experientes. Não houve relato de abandono da profissão, excetuando-se os que se tornaram incapazes para o trabalho. Mapeada por meio de entrevistas compostas de perguntas orientadoras realizadas pelo autor, é possível identificar traços da experiência vivida pelo trabalhador, suas ações, causas e consequências. O estudo desses dados, junto com o conhecimento dos pesquisadores, revela respostas para acontecimentos que não são registrados, e ajuda a sanar algumas dúvidas a respeito da profissão. As perguntas orientadoras foram decorrentes da observação não participativa do pesquisador no sentido de conhecer o cotidiano da profissão, bem como despontar a dramática e estratégias de regulação desses profissionais. As questões básicas foram: Como é ser motociclista profissional? Quais os pontos positivos e negativos da profissão? Você já se acidentou alguma vez? Quais são suas expectativas profissionais? 0 tempo de contato médio com os entrevistados foi de três dias com cada motociclista profissional.

Levando em consideração os relatos de História de Vida individuais, podemos caracterizar pontos de vista comuns para indivíduos pertencentes a um mesmo grupo social. Assim, segundo Caldeira (1980) apud MENEGHEL (2007):

\footnotetext{
"No ato de solicitar a alguém que relate sua vida está contido um reconhecimento da individualidade, um respeito àquela vida que afinal não é qualquer vida, mas uma vida particular: a sua vida. E a entrevista dá voz, tira do anonimato uma vida marcada pelo sofrimento, pela angústia, pela luta: uma vida cujo relato só pode ser marcado pelo sofrimento, pois além de ser sua parte integrante, é ele que de alguma maneira lhe confere dignidade".
}

Para este estudo buscou-se levar em conta o momento histórico vivido pelo sujeito, segundo suas palavras. De acordo com Thompson (1992), as informações que virão à público, devem ser trabalhadas unicamente para melhoria do texto, não sendo as palavras o interesse principal, mas sim o que elas contêm. 
Segundo Brioschi e Trigo (1987), para a construção deste tipo de estudo é necessário o histórico (a temporalidade contida no relato individual remetente ao tempo histórico), dialeticidade (prática e teoria colocadas em confronto durante a investigação) e dinamicidade (abranger a composição das relações sociais e seus processos de mudança). ${ }^{5}$

\section{CAMPO DA PESQUISA}

O local, recorte para o estudo, foi escolhido em razão de ser a quarta cidade de Minas Gerais que apresentou maior número de acidentes de trânsito, de acordo com os dados do Diagnóstico de Acidentes de Trânsito Minas Gerais ${ }^{6}$ (2014-2015a) e no Monitoramento de Acidentes de Trânsito Minas Gerais ${ }^{7}$ (2014-2015b), ambos da Secretaria de Estado de Defesa Social (SEDS), com intuito de análise dos pontos em comum nos depoimentos dos MP's, testemunhos os quais, posteriormente, foram confrontados e utilizados para descobrir causas para os acidentes, assim como propor possíveis soluções.

\section{OS MOTOCICLISTAS PROFISSIONAIS}

Inicialmente foram feitas buscas nas bases de dados científicas: Scielo, PubMED, IEEExplore, com as palavras-chave: Motoboys, Motociclistas Profissionais, Acidentes de Trabalho, Acidente de Trânsito, Saúde do Trabalhador, nos idiomas Português e Inglês, com a utilização dos descritores boleanos "e" "ou". Após consultas sobre a profissão e seleção dos artigos científicos, analisou-se as estatísticas que constam no DATASUS ${ }^{8}$ em relação ao número de motociclistas que foram vítimas fatais em acidentes de colisão no Brasil (cerca

\footnotetext{
${ }^{5}$ Aos participantes foram explicados os riscos e benefícios da pesquisa, assegurado a confidencialidade dos dados com posterior assinatura do Termo de Consentimento Livre e Esclarecido (TCLE).

${ }^{6}$ Dados pesquisados no site http://www.seds.mg.gov.br/integracao/estatisticas/estatisticas-de-transito (Acesso em 20/11/2016)

${ }^{7}$ Dados pesquisados no site http://www.seds.mg.gov.br/integracao/estatisticas/estatisticas-de-transito (Acesso em 20/11/2016)

${ }^{8}$ Estatísticas que constam no site do DATASUS. Disponível em:

$<$ http://tabnet.datasus.gov.br/cgi/deftohtm.exe?sim/cnv/ext10mg.def>. (Acessado em 21/11/2016)
} 
de 370 casos em 2014, do total de acidentes de colisão com veículos motorizados), e de reportagens sobre os acidentes com motociclistas ${ }^{9}$.

Para obtenção das informações e reconhecimento do contexto que envolve o trabalho dos MP, inicialmente entrevistou-se dois profissionais que trabalham na referida ocupação há quatro e oito anos. Os mesmos relataram o cotidiano da profissão, bem como três aspectos relevantes os quais, o presente estudo tomou como diretiva para abordagem da problemática, que envolve: aqueles que trabalham e nunca sofreram acidentes de colisão (M1), os que já sofreram acidentes de colisão e continuam trabalhando (M2), e, aqueles que já sofreram acidentes de colisão e ficaram incapacitados "permanente" para exercer a profissão (M3). Em seguida, recrutou-se três motociclistas profissionais com as respectivas características supracitadas para que, por meio da História de Vida, os mesmos pudessem relatar a vivência na ocupação, a fim de identificar os principais motivos de ocorrer tais acidentes, de acordo com sua visão.

Os entrevistados foram escolhidos segundo indicações de clientes e pessoas a que prestam serviço, sobre sua eficiência no trabalho. M1 e M3 eram celetistas e trabalhavam na mesma empresa. Suas idades eram 22 e 28 anos e quatro e dez anos de serviço como MP, respectivamente. M2 era autônomo e tinha 31 anos de idade e 16 anos de profissão como MP. Os encontros foram realizados individualmente em um ambiente que não tivesse vínculos com o seu trabalho, em dias e horários previamente combinados.

Durante os encontros, os três entrevistados demonstraram grande interesse no tema abordado pelo fato de ser constituído sobre os depoimentos e as opiniões dos mesmos em relação ao trabalho que realizam ou realizaram. Ressalta-se que isso evidencia a vivência dos profissionais frente aos bons momentos bem como às intercorrências que ocorrem durante a prática laboral.

A pesquisa buscou uma inserção no universo dos entrevistados, tentando entender todo o sentimento que os mesmos tinham ao apresentarem os seus relatos, bem como a forma como descreviam a sua atividade, como percebe-se no relato segundo M2: "Tem que gostar muito, porque você sai de casa não sabe se volta. Isso ai é fato".

\footnotetext{
${ }^{9}$ Como exemplo http://ocponline.com.br/noticias/sepultado-corpos-de-motociclistas-que-faleceramaposacidentes-na-sexta
} 


\section{Carvalho et al.}

Todos os entrevistados foram esclarecidos quanto ao objeto e objetivo do presente estudo e cada um deles assinou o termo de consentimento livre e esclarecido, no qual concedeu autorização para o uso de suas falas para análise do tema proposto e em eventuais publicações científicas.

\section{Relatos}

Segundo Silva et al. (2007), o fato de se trabalhar como motociclista profissional se deve a uma solução para o desemprego (sobrevivência), em um mercado cada vez mais excludente para a população masculina e jovem (principalmente), embora também se considere que muitos valorizam a ocupação pelo fato de trazer emoções, pela necessidade de imposição de coragem e velocidade, características altamente valorizadas por eles.

Inicialmente foram apresentados os motivos que os levaram a optar por este trabalho, tendo em vista todo o histórico de acidentes, por aqueles que já sofreram, e outros comentários a respeito dos riscos, periculosidades e penosidades existentes na prática da profissão. Mesmo (re)conhecendo todas as intercorrências do trabalho, os entrevistados após responderem aos questionamentos em relação a um determinado aspecto, logo em seguida, buscavam fornecer os pontos positivos da profissão, destacando seu prazer e satisfação por poderem trabalhar nesta atividade, tal como expressa M1:

"[...] a profissão de motoboy é bem perigosa. [...]Eu gosto de trabalhar como motoboy. Tem [Eu tenho] todas [as] motivações então". (M1)

Similarmente, M3 afirma:

"[...]é perigoso, mas ao mesmo tempo é divertido. Eu gostava do serviço que eu fazia". (M3)

Diante disso, buscou-se entender quais seriam os pontos negativos sob a perspectiva do trabalhador e seu enfrentamento frente às adversidades de ser MP. Considerando a seguinte afirmação de M1: 
Riscos do trabalho dos motociclistas profissionais:

estratégias de prevenção e regulação

"Encontrar com muitos motoristas fazendo o que não pode. Porque quando você pilota, não pilota só pra você. Você pilota pro mundo inteiro. É um carro que está vindo, uma criança que pode passar, uma bola que pode cair. Então[ ], é manter atenção ao máximo sempre pra não acontecer nada de[...] nenhum acidente conosco" (M1);

Percebe-se que todos os atores sociais do trânsito interferem diretamente nas atividades e, consequentemente, na forma de prevenção dos acidentes e na segurança dos MP. Somando-se a isso, os motociclistas profissionais precisam a todo instante fazer uso de si por si e auto normatizarem frente aos constrangimentos apresentados no contexto laboral. Segundo Schwartz (2000) "[...] o trabalho envolve sempre o uso de si. Há uso de si pelos outros, já que o trabalho é, em parte, heterodeterminado por meio de normas, prescrições e valores constituídos historicamente".

Observa-se que no exercício da atividade, os trabalhadores realizam a gestão de si mesmos e de sua relação com o coletivo de trabalho, além das diversas interfaces que interatuam no meio (o próprio instrumental de trabalho, outros motoristas, policiais, condições da via, características tempo - chuva/sol, etc). O trabalho é individual e exposto à intensificação (baixo valor da corrida) e com carga de trabalho elevada (tanto física, psíquica e cognitiva).

O fator tempo é outro elemento presente nas situações de trabalho dos motociclistas profissionais. Os prazos exigidos pelos clientes estão presentes em cena todo momento, o que contribui para a existência de uma pressão no trabalho. Conforme Guérin et al. (2001), o tempo é um dos elementos essenciais que determinam os modos operatórios. Schwartz (1996) afirma que toda forma de atividade, em qualquer circunstância, sempre apresenta variáveis para serem geridas e que todas essas situações são sempre singulares e históricas, onde o indivíduo tem que fazer escolhas.

Outro ponto negativo destacado pelos participantes, durante as entrevistas, é a dicotomia na opinião das pessoas sobre o trabalho dos MP, que mesmo sendo de fundamental e imprescindível importância, passam por mal-estar causado pela exposição dos mesmos frente aos constrangimentos da atividade, o qual pode ser um dos fatores contribuintes para os acidentes no trânsito. 
Embora os motociclistas profissionais sejam taxados de ousados, irresponsáveis e imprudentes, este é o caminho possível para "dar conta" dos constrangimentos impostos pelo meio social. O baixo valor social do trabalho aliado às impossibilidades de sua execução, frente ao que é estabelecimento socialmente pelas normas, resulta nos acidentes e incapacidades nesta população trabalhadora.

Assim, esse conflito no trânsito também se explica devido aos demais motoristas não se imaginarem no lugar dos MP's, realizando as ações necessárias para o trabalho, que acabam causando uma opacidade no ponto de vista dos demais motoristas em relação aos entregadores. Como narrado no depoimento de M3:

"As pessoas têm mania de falar que motoqueiro é tudo doido por correr demais, mas às vezes a pessoa tá ligando pra pedir entrega porque está com pressa". (M3)

Podendo resultar em casos como descritos por M2:

"Rola muito de segurar muito em cima. Carro joga pro lado, e na hora que vê que vai te acertar, coloca seta pra dizer que estava com a seta ligada" (M2).

Frente ao cotidiano dos MP, o ponto no qual disseram que ocorre maior número de críticas acontece quando estão dirigindo no espaço entre os carros no trânsito, os chamados “corredores", para otimizar o tempo das entregas. De acordo com os entrevistados, estas dificuldades ocorrem pela falta de preocupação das pessoas com a possibilidade de haver um MP transitando no momento, como descrito por M1:

"Toda a culpa é do motoboy. Na hora que você está no corredor, os outros que te fecham. As pessoas abrem a porta do carro para pegar alguma coisa no chão na hora que você tá vindo no corredor [...]". (M1)

Mesmo diante dos riscos dentro de um "corredor", os MP's ainda julgam fundamental dirigir nesses espaços, uma vez que este é, segundo os mesmos, um dos motivos que apontam a necessidade do profissional. Conforme M2:"Se a gente for parar atrás de cada carro, então não precisa de motoboy". 
Devido ao fato de muitas vezes o serviço não ser prestado seguindo registros e normas, o estudo de Grisci, Scalco e Janovik (2007) adicionam que "a velocidade não visualizada no registro da profissão é, entretanto, visualizada nas ruas e nas falas dos MP's, que veem, na velocidade da entrega, o sentido do seu trabalho", podendo ser este classificado por eles como mais um dos motivos de existência da profissão para sanar a demanda do mercado.

Durante as entrevistas os tipos de acidentes mais falados aconteceram pela falta de atenção por parte de todos os participantes no trânsito, ou seja, os motoristas, os pedestres, os ciclistas, os motociclistas, entre outros. Tentando justificar suas opiniões, M2 e M3 descreveram acidentes que vivenciaram:

"Um dia eu indo de moto, na hora que eu entro à direita, um Corsa me pega de frente! Como que eu ia evitar isso se a mão era só minha?". (M2)

\begin{abstract}
"Bati num ônibus e o cara que me esbarrou estava conversando no celular. 0 acidente cortou a minha perna em oito centímetros, fraturei o fêmur, estou com uma placa que está segurando a dobra do joelho. Quebrei o joelho em três partes, e não tenho mais a rótula. Eu não tenho mais firmeza pra aguentar o peso de uma moto". (M3)
\end{abstract}

No estudo transversal de abordagem quantitativa analítica, feito por Paula, Camargo e Iwamoto (2015), foram considerados como desfechos do trabalho a exposição a agressões verbais, violências no trânsito e acidentes de trânsito, os quais seriam advindos de características demográficas, condições de trabalho e de saúde.

Como exposto por Soares et. al. (2011), os acidentes que envolvem MP's não estão unicamente ligados ao seu comportamento, mas também com o meio e regras de mercado estabelecidas pelos contratantes do serviço, mas dentre todos os meios de prevenção e proteção descritos pelos entrevistados, podemos destacar que a origem dos acidentes de colisão envolvendo motociclistas profissionais está diretamente ligada à falta de atenção de todas as pessoas que participam do trânsito. Mesmo havendo uma conscientização teórica nas autoescolas a respeito da direção defensiva, essa pode acabar se tornando despreocupante e irrelevante após a formação do condutor, por falta de abordagem do assunto no cotidiano e pela repetição habitual das ações durante a direção. 
A estrutura da organização define o conjunto de interações entre as pessoas e os coletivos que as fazem viver (DANIELLOU, SIMARD \& BOISSIÈRES, 2010). O meio social criou a demanda pelo trabalho dos motociclistas profissionais, mas, infelizmente, não se criou o espaço social para que o trabalho pudesse ser realizado. Em uma organização há a possibilidade de uma coexistência relativa entre lógicas que podem ser diferentes sendo, ao mesmo tempo, uma estrutura e um conjunto de atividades de interações entre os trabalhadores, que podem permitir a gestão e a aplicação ou evolução de regras nos ambientes de trabalho, em suas situações (PEREIRA, 2017).

\section{Uma visão externa}

De acordo com Tebaldi e Ferreira (2004), devido à imprudência e a irresponsabilidade na direção de alguns, os motoristas representam um problema de saúde pública, falta de segurança e agressividade.

Os depoimentos orais de cada um dos entrevistados auxiliaram a expor o ponto de vista dos MP's, os quais viveram situações diferentes entre si, mas que foram tipos de acontecimentos comuns destacados dentro do trabalho. Com a análise desta pesquisa podese encontrar motivos de acidentes e formas utilizadas pelos MP's para sua prevenção, com o objetivo de propor possíveis soluções para este tema.

Frente aos comentários dos grupos já entrevistados, e tendo como objetos de análise a falta de atenção de todas as pessoas que fazem parte do trânsito, em conjunto com a baixa empatia dessas pessoas em relação aos motociclistas profissionais, entrevistou-se um profissional de outro ramo de atividade que utiliza um automóvel para sua atividade laboral diária, para que este expusesse seu ponto de vista a respeito do comportamento dos MP's no trânsito.

O condutor do automóvel entrevistado (C1) destacou que para prevenção de acidentes envolvendo MP's, os próprios não deveriam dirigir de maneira agressiva. Em acréscimo, aponta ainda a necessidade de elevar a atenção no trânsito, como apresentado a seguir: 
Riscos do trabalho dos motociclistas profissionais:

estratégias de prevenção e regulação

"Os motoboys em si eu acho que devia ser proibido bastante coisa do que eles fazem. Não gosto de motoboy, acho que eles abusam demais. A direção deles é bastante ofensiva. Atrapalha o carro na hora que está dirigindo porque se a gente está andando e eles vem rápido, a gente tem que ficar olhando mais e tomando mais cuidado, porque um esbarrão nosso neles é mais perigoso. Eu acho que devia ser proibido bastante coisa do que eles fazem, não pra motorista". (C1)

Esta descrição permite elucidar um ponto de vista similar ao dos MP's com relação à atenção que os motoristas de automóveis deveriam ter. Como descrito no estudo de Sprenger et al. (2015), a atenção, por ser relacionada à percepção, enquadra-se como essencial para o motorista durante a direção, podendo esta auxiliar na tomada de decisões.

Entretanto, nota-se que C1 responsabiliza o comportamento dos motociclistas pela ocorrência de situações que requerem um maior índice de atenção. Não obstante, foi apresentado anteriormente o motivo pelo qual a categoria dos entrevistados se comporta da maneira descrita. A profissão que, como afirmada no estudo de Grisci, Scalco e Janovik (2007): "sendo o motofrete uma profissão assumidamente de risco e com um alto número de acidentes registrados todos os dias nas grandes cidades, percebe-se uma movimentação no sentido de dirigir um olhar mais atento a esses trabalhadores, que tomam conta das ruas da cidade e disputam espaço com carros e pedestres", é vista pelos motoristas como perigosa, devido as possibilidades de acidentes com seus profissionais. Entretanto pode-se perceber que $\mathrm{C} 1$, mais que desconhece ou ignora a situação de trabalho dos motociclistas profissionais e as condições que levam aos motivos mencionados, não vivencia a dramática do cotidiano laboral profissional, pois o mesmo tem uma visão "protegida“" pela sua "armadura" do automóvel, a qual distancia o saber-fazer do cotidiano de exposição a riscos e constrangimentos a que os MP's estão sujeitos.

\section{CONSIDERAÇÕES FINAIS}

Essa lógica de se produzir mais em menor tempo é um dos fatores explicativos das condições geradoras dos acidentes que envolvem essa população analisada. Este profissional tem que lidar ao mesmo tempo com as metas de produção, a satisfação do cliente, a relação 
com o trânsito e a sua autoproteção, nem sempre bem-sucedida, contra os acidentes no trânsito.

As possibilidades de atuações contributivas para redução do número de acidentes com os MP's e a melhoria de comportamento dos motoristas dentro do trânsito são reflexos de medidas que envolvam, não só os motoboys, mas todos os participantes deste problema. É necessário criar ações para resolução de grande parte dos pontos negativos relacionados a esse ambiente, mas com a participação de todos os atores envolvidos, a fim de auxiliar na prevenção de acidentes, respeito às leis de trânsito e práticas que reflitam em saúde e segurança no trânsito.

A transformação dessa realidade é possível. Mudanças, porém, não dependem somente da transformação intrínseca do "ser" e do "fazer" dessa categoria. Novas soluções são necessárias para reverter os constrangimentos materiais, organizacionais e sociais a que os motociclistas profissionais estão expostos. Essa deve ser uma construção coletiva com o uso de saberes dos atores envolvidos que reflitam em saúde e segurança para este contexto produtivo. A Educação no Trânsito, associada à melhoria da Organização do Trabalho (OT) na qual estes atores estão expostos, devem ser as premissas deste processo, permitindo que os motociclistas prestem serviço com agilidade, mas sem necessidade de assumir comportamentos de alto risco.

As relações estabelecidas envolvem integrar a população no meio social, criando espaços sociais para que a atividade possa ser desenvolvida. É necessário sim criar medidas educativas no trânsito, espaços para circulação de motociclistas, porém, também é necessário criar políticas que favoreçam o emprego, com o intuito de se quebrar essa lógica de se produzir a qualquer custo (constrangimento de tempo que se desdobra em transgressões - com margens de regulação muito restritas) - tendo que se regular sobre "duas rodas" todas as contradições oriundas do meio social. Como dito por Diniz (2005, p.50), "o número crescente de motociclistas profissionais, os riscos de acidentes que eles vivenciam rotineiramente [...] colocam em xeque as tradicionais políticas públicas praticadas e as propostas de intervenção formuladas pelos atores sociais envolvidos com a questão". 


\section{REFERÊNCIAS}

BRASIL. Ministério da Saúde: Blog da Saúde. Brasil é o quinto país no mundo em mortes por acidentes no trânsito. Ministério da Saúde. [online]. 2015. Disponível em: <http://www.blog.saude.gov.br/35535-brasil-e-oquinto-pais-no-mundo-emmortes-por-acidentes-no-transito.html>. Acesso em: 23 maio 2016.

BRASIL. Ministério das Cidades. Departamento Nacional de Trânsito - DENATRAN. Frota de Veículos. Ministério das cidades. [online]. 2016. Disponível em: <http://www.denatran.gov.br/index.php/estatistica/237-frota-veiculos>. Acesso em: 15 out. 2016.

BRASIL. Ministério da Saúde DATASUS. Informações de Saúde. Estatísticas vitais. óbitos por causas externas: Minas Gerais. Ministério da Saúde. [online]. 2014. Disponível em: <http://tabnet.datasus.gov.br/cgi/deftohtm.exe?sim/cnv/ext10mg.def>. Acesso em: 21 out. 2016.

BRIOSCHI, L. R.; TRIGO, M. H. B. Relatos de vida em ciências sociais: considerações metodológicas. Ciência e cultura. [S.l.], v. 39, $\quad$ n. 7, p. 631-637, $1987 . \quad$ Disponível em: <http://www.scielo.br/scielo.php?script=sci_nlinks\&ref=000118\&pid=S0034-7167200500020000500015\&lng=pt>. Acesso em: 21 out. 2016.

DANIELLOU, F.; SIMARD, M.; BOISSIÈRES, I. Fatores humanos e organizacionais da segurança industrial: um estado da arte. (R. Rocha, F. Lima, \& F. Duarte, Trad.). Cadernos da Segurança Industrial. Toulouse: FONCSI, 2010.

DINIZ, E. P. H.; ASSUNÇÃO, A. A.; LIMA, F. P. A. Prevenção de acidentes: o reconhecimento das estratégias operatórias dos motociclistas profissionais como base para a negociação de acordo coletivo. Ciênc. saúde coletiva. [S.1.], v. 10, n. 4, p. 905-916, 2005. Disponível em: <http://www.scielo.br/scielo.php?script=sci_arttext\&pid=S141381232005000400014>. Acesso em: 27 out. 2016.

DRUMOND MORAES, T. Fatores de risco de acidentes na atividade dos motoboys: limites das análises quantitativas. InterfacEHS-Revista de Saúde, Meio Ambiente e Sustentabilidade. [S.l.], v. 3, n. 3, 2008. Disponível em: <http://www.revistas.sp.senac.br/index.php/ITF/article/view/127/144>. Acesso em: 27 out. 2016

FRITZKE, W. Sepultado corpos de motociclistas que faleceram após acidentes na sexta. [online]. Disponível em: <http://ocponline.com.br/noticias/sepultado-corpos-de-motociclistas-que-faleceramapos-acidentes-na-sexta/>. Acesso em: 27 out. 2016.

GRISCI, C. L. I.; SCALCO, P. D.; JANOVIK, M. S. Modos de trabalhar e de ser de motoboys: a vivência espaço-temporal contemporânea. Psicologia Ciência e Profissão. [S.1], v. 27, n. 3, p. 446-461, 2007. Disponível em: $<$ http://www.scielo.br/scielo.php?pid=S1414-98932007000300007\&script=sci_abstract\&tlng=pt>. Acesso em: 21 out. 2016.

GUÉRIN, F.; LAVILLE, A.; DANIELLOU, F.; DURAFFOURG, J.; KERGUELEN, A. Compreender o trabalho para transformá-lo: a prática da ergonomia. São Paulo: Editora Edgard Blücher, 2001.

MALÁSIA. World Health Organization - WHO. Road traffic injuries. World Health Organization. [online]. Disponível em: <http://www.who.int/mediacentre/factsheets/fs358/en/>. Acesso em: 5 out. 2016.

MENEGHEL, S. N. Histórias De Vida - notas e reflexões de pesquisa. Athenea Digital. [S.l.], n. 12, p. 115-129, 2007. Disponível em: <http://atheneadigital.net/article/view/n12-meneghel>. Acesso em: 21 out. 2016.

MENEGOLO, E.D.C.W; CARDOSO, C.J.; MENEGOLO, L.W. O uso da história oral como instrumento de pesquisa sobre o ensino da produção textual. Ciências \& Cognição. [S.l.], v. 9, p. 02-13, 2006. Disponível em: <http://www.cienciasecognicao.org/revista/index.php/cec/article/view/596>. Acesso em: 21 out. 2016.

MINAS GERAIS. Secretaria de Estado de Defesa Social (SEDS). Centro Integrado de Informações de Defesa Social CINDS. Diagnóstico De Acidentes De Trânsito Minas Gerais (2014 - 2015a). Belo Horizonte. abr. 2016. Disponível em: <http://www.seds.mg.gov.br/integracao/estatisticas/estatisticas-de-transito>. Acesso em: 20 out. 2016.

MINAS GERAIS. Secretaria de Estado de Defesa Social (SEDS). Centro Integrado de Informações de Defesa Social CINDS. Monitoramento de Acidentes de Trânsito - Minas Gerais (2014-2015b). Belo Horizonte, jul. 2015. Disponível em: <http://www.seds.mg.gov.br/integracao/estatisticas/estatisticas-de-transito>. Acesso em: 20 out. 2016. 
PAULA, G. F.; CAMARGO, F. C.; IWAMOTO, H. H. Condições de saúde e trabalho e exposição à violência no trânsito entre mototaxistas. Revista de Enfermagem e Atenção à Saúde. [S.l.], v. 4, n. 2, 2015. Disponível em: <http://saudepublica.bvs.br/pesquisa/resource/pt/bde-27407>. Acesso em: 20 out. 2016.

PEREIRA, A.; MENDES, D.; MORAES, G. Do prescrito ao real: a imprevisibilidade e a importância do trabalho coletivo em um centro de usinagem de uma empresa metal-mecânica do interior do Estado de Minas Gerais. Laboreal, 13 (1), 24-38, 2017. Disponível em: <http://dx.doi.org/10.15667/laborealxiii0117ep>. Acesso em: 27 set. 2017.

SCHWARTZ, Y. Trabalho e valor. Tempo social. 8, 2, 147-158, 1996 . Disponível em <https://doi.org/10.1590/ts.v8i2.86429>. Acesso em: 27 set. 2017.

SCHWARTZ, Y. Trabalho e uso de si. Revista Pro-posições, Faculdade de Educação, Unicamp, 32. São Paulo. 2000. Disponível em: <https://periodicos.sbu.unicamp.br/ojs/index.php/proposic/article/view/8644041>. Acesso em: 20 out. 2016.

SILVA, A.P.; BARROS, C.R.; NOGUEIRA, M.L.; BARROS, V.A. "Conte-me sua história": Reflexões sobre o método história de vida. Mosaico: Estudos em Psicologia. [S.l.], v. 1, n. 1, p. 25-35, 2007. Disponível em: <https://seer.ufmg.br/index.php/mosaico/article/view/4344>. Acesso em: 14 nov. 2016.

SILVA, D. W.; SOARES, D. A.; ANDRADE, S. M. Atuação profissional de motoboys e fatores associados à ocorrência de acidentes de trânsito em Londrina-PR. Epidemiol e Serv Saúde, Brasília, v. 17, n. 2, p. 123-153, 2008. Disponível em: <http://scielo.iec.pa.gov.br/pdf/ess/v17n2/v17n2a10.pdf>. Acesso em: 20 maio 2016.

SOARES, D.F.P.P.; MATHIAS, T.A.F.; SILVA, D.W.; ANDRADE, S.M. Motociclistas de entrega: algumas características dos acidentes de trânsito na Região Sul do Brasil. Rev. bras. Epidemiol. São Paulo, v. 14, n. 3, p. 435-444, set. 2011. Disponível em: <http://www.scielo.br/scielo.php?script=sci_arttext\&pid=S1415-790X2011000300008>. Acesso em: 14 nov. 2016.

SPINDOLA, T.; SANTOS, R. S. Trabalhando com a história de vida: percalços de uma pesquisa (dora?). Revista da Escola de Enfermagem da USP. São Paulo, v. 37, n. 2, p. 119-126, jun. 2003. Disponível em: $<$ http://www.ee.usp.br/reeusp/upload/pdf/207.pdf>. Acesso em: 14 nov. 2016.

SPRENGER, D.; COSTA, L.; BORGES, A.; PESSOTO, F.; MONTIEL, J.M.; BARTHOLOMEU, D.; HEITOR, D.; TEALDI, L.L. Avaliação da atenção em uma amostra de motociclistas. Salud \& Sociedad. [S.l.], v. 6, n. 1, p. 10-20, 2015. Disponível em: <http://revistas.ucn.cl/index.php/saludysociedad/article/view/916>. Acesso em: 17 fev. 2016.

TEIXEIRA, J.R.B.; BOERY, E.N.; ARAÚJO, T.M.; MOTA, T.N.; CASOTTI, C.A.; BOERY, R.N. Traffic accidents and the use of individual protection equipment for motorcycle taxis: an integrative review. Journal of Nursing UFPE on line. [online], $\quad$ v. $\quad 9, \quad$ n. $\quad 2, \quad$ p. $\quad 945-956, \quad 2014 . \quad$ Disponível em: <http://www.revista.ufpe.br/revistaenfermagem/index.php/revista/article/viewArticle/ 5496>. Acesso em: 25 fev. 2016.

TEBALDI, E.; FERREIRA, V. R. T. Comportamentos no trânsito e causas da agressividade. Revista de Psicologia da UnC. [S.l.], v. 2, n. 1, p. 15-22, 2004. Disponível em: <http://apatru.org.br/arquivos/\%7B2A8F9EAD-10B9-4B92-9AB22594D4496AE9\%7D_32.pdf>. Acesso em: 14 nov. 2016.

THOMPSON, P. História oral: a voz do passado. 2 ed. Tradução de: Lólio Lourenço de Oliveira. Rio de Janeiro: Paz e Terra. Rio de Janeiro, v. 388, n. 229, 1992.

TONI, M. Visões sobre o trabalho em transformação. Sociologias, Porto Alegre, Ano 5, n.9, jan/jun 2003, p.246-286. Disponível em: <http://www.scielo.br/pdf/soc/n9/n9a09.pdf>. Acesso em: 14 nov. 2016.

VERONESE, A. M.; OLIVEIRA, D. L. L. C. Os riscos dos acidentes de trânsito na perspectiva dos moto-boys: subsídios para a promoção da saúde. Cad. Saúde Pública. Rio de Janeiro, v. 22, n. 12, p. 2717-2721, dez. 2006. Disponível em: <http://www.scielo.br/pdf/csp/v22n12/20.pdf>. Acesso em: 14 nov. 2016. 